\title{
Start-up Goals of Nongjiale Operators in China
}

\author{
Xiuhong Wang \\ Department of Tourism Management Henan Vocational College of Agriculture, No.38 Youth Road, Zhongmu County, \\ Zhengzhou City, China \\ wangyuming03@163.com
}

\begin{abstract}
Based on the investigation into the start-up goals of entertainment-oriented Nongjiale operators in the suburbs of Shanghai, Wuhan and Chengdu and comparative analysis of its results, conclusions were reached that the start-up goals of Nongjiale operators in the suburbs of the above three cities share the characteristics of rural tourism in its initial stage, that is, strong flavor of rural life, more concern about short-term economic and social goals but less concern about long-term economic goals and self achievement, but there are also some differences in business format due to different developmental stages, regional economy, governmental supports and practical operation performances in three cities. This study can be of some practical and theoretical significance to the healthy development of rural tourism both in three cities and in China.
\end{abstract} study

Index Terms - Nongjiale, operators, start-up goals, empirical

\section{Introduction}

Nongjiale is one very unique form of rural tourism in China.Rural tourism originated in Europe in the 19th century [1]. Modern rural tourism in China dates back to 1987 when the first Peach Blossom Festival was successfully held in Chengdu of Sichuan Province[2]. The rapid development of rural tourism in China benefits from villagers' ambitions to get rich and government supports, but overseas studies show that rural tourism plays a rather limited part in improving the operators' family economy

\section{Rural Tourism and Operators' Start-up Goals}

\section{A. Rural Tourism}

Overseas scholars' opinions vary on the definition of rural tourism. A typical definition, however, was given by EU and OECD, which says that rural tourism refers to tourist activities occurring in the countryside, and in which rurality is further regarded as the overall core and selling point of rural tourism [3].

There is no agreement on the definition of rural tourism in China, either. Quite a lot of scholars tend to consider rural tourism to be limited to tourist activities around the farmyard, that is, a tourist form that farmers make use of the rural scenery and natural scenic spots around their own farmyard to attract tourists. Such a definition is obviously behind the practice of rural tourism. Nowadays, rural tourism operators include not only farmers, but also the nation, the collective, urban residents and foreign investors. Besides, places for operation are not confined to operators' own farmyards any longer; there has been a tendency to shift to scenic spots or peripheral areas with beautiful scenery and convenient transportation, and thereby farm hotels in scenic spots and rural tourism in the periphery of the scenic spots has come into being [4].

This article favors the definition of rural tourism in its narrow sense, that is, rural tourism refers to tourism occurring in the countryside and taking the natural and human landscape in rural areas as tourist attractions, in which two aspects must be included, that is, the countryside background, and natural landscape or human attractions.

\section{B. Start-up Goals}

Start-up goals, the goals pursued by rural tourism operators at the very beginning of their business, mainly include lifestyle, money, social life and self-reliance. For the convenience of analysis, the above four recessive goals were further divided into eleven dominant goals. Operators finished filling out the questionnaire by choosing each most proper one from the five choices of each dominant goal with different approval degrees from "absolutely agree", "agree" , "hard to say" , "don't agree" to "not agree at all" (evaluation marked as 5, 4, 3, 2, 1 in turn). In the end, related conclusion about rural tourism operators' start-up goals was reached through the analysis of the results of the eleven dominant goals belonging to the four recessive goals. The start-up goals in this article were designed by modifying Donald Getz and Jack Carlsen's design of rural tourism operators' goals in Australia [5].

\section{Overall Analysis of Start-up Goals}

Through overall analysis into the four recessive goals (lifestyle, money, social life and self-reliance) and eleven dominant goals, it was concluded that the overall characteristics of the start-up goals of rural tourism operators in Shanghai, Wuhan and Chengdu were as follows.

\section{A. Recessive Start-up Goals}

The approval degrees and percentages of the four recessive goals -lifestyle, money, social life and self-relianceare $4.085,3.927,4.160,3.717$ and $77.7 \%, 72.6 \%, 80.9 \%$, $62.8 \%$ respectively. High approval degree and approval percentage show operators' overall approval of the start-up goals in rural tourism.

The mean approval degree of lifestyle(4.085) and its mean approval percentage $(77.7 \%)$ are higher than those of money $(3.927,72.6 \%)$ and those of self-reliance (3.717, $62.8 \%$ ), which indicates that to profit from rural tourism to realize economic independence is based on the operators' fondness for rural life. High mean approval degree (4.160) and high mean percentage $(80.9 \%)$ in the goal to get acquainted 
with more interesting people (social life) show that operators have rather strong motivation for social life while managing their farm hotels.

\section{B. Dominant Start-up Goals}

Except that rural tourism operators in the three cities have low approval percentage and low approval degree in the goal to be able to be a boss $(47.0 \%, 3.21)$, the approval percentages and degrees of the other ten dominant goals are all higher than $60 \%$ and 3.60, which further enhanced rural tourism operators' overall approval of the start-up goals.

Operators' lowest mean approval percentage of dominant start-up goals is to be able to be a boss (47.0\%), and the highest $(88.2 \%)$ is to live in rural environment we like, the disparity amounting to $41.2 \%$; the lowest mean approval degree is 3.21 (to be able to be a boss), and the highest is 4.40 (to live in rural environment we like), the disparity amounting to 1.19. The big gap between the two groups of data combined with high approval percentage and degree in the goal to earn much money (money) $(76.5 \%, 4.03)$, in the goal to earn retirement income $(69.1 \%, 3.79)$, in the goal to take farm hotels as family property $(72.1 \%, 3.96)$ and in the goal to get acquainted with more interesting people $(60.3 \%, 3.65)$, fully demonstrated the characteristics of rural tourism in the three cities in its initial stage, namely, being sentimentally attached to country life, too much concern about economic benefit but insufficient concern about self achievement.

The above shows that rural tourism operators in the three cities take positive attitude to the start-up goals. Strong attachment to rural life, too much concern about economic goals while insufficient concern about self achievement, and strong motivation for social life demonstrated the characteristics of rural tourism in its initial stage. The reasons why operators start farm hotels are mainly to make money, to get to know more people, and to be economically independent.

\section{Comparative Analysis of Start-up Goals}

Through comparative analyses into the four recessive goals and the eleven dominant goals, it was concluded that the similarity and difference of the start-up goals of farm hotel operators in Shanghai, Wuhan and Chengdu were as follows.

\section{A. Lifestyle}

The lifestyle goal is the most prominent one among the four recessive start-up goals in the three cities. The mean approval degrees to live in rural environment we like and to enjoy a lifestyle we like are 4.40 and 4.22 , the mean approval percentage coming up to $88.2 \%$ and $85.3 \%$ respectively, which indicates that most operators start their farm hotels because they like rural environment and rural life. The mean approval degree of another goal of lifestyle, to satisfy our leisure interests, is 4.04, and the mean approval percentage $73.6 \%$, which shows that most operators take their interests and hobbies into consideration when starting the business. There is little approval of the goal to keep my family together with the percentage of a little more than $60 \%$, while $23.5 \%$ operators takes negative attitude to that goal. Besides, the approval degree is only 3.68. On the one hand, this reflects operators' lack of knowledge about rural tourism when it is at its early stage. On the other hand, this shows that at the beginning, the scale of rural tourism is not large enough, its operation has not fulfilled their expectations, the attendance of the other members of the family is rather low, so family cohesion caused by rural tourism is still rather limited.

The two dominant goals of the recessive goal lifestyle - to live in rural environment and to enjoy a lifestyle we like - are related with operators' values and the operation performances. The approval percentages of the two goals by operators in Shanghai, Wuhan and Chengdu are $88 \%, 89.5 \%, 87.5 \%$ and $88 \%, 84.2 \%, 83.4 \%$ respectively, which demonstrates the similarity that rural tourism operators in the above three cities are sentimentally attached to rural life. The mean approval degree of the two goals in Shanghai and Chengdu are 4.72, 4.44 and $4.54,4.71$ respectively, obviously higher than that $(3.79,3.32)$ in Wuhan. Such obvious difference shows that farm hotels in Shanghai and Chengdu, which benefit from its earlier beginning of operation, or government's positive support, while the operation of farm hotels in Wuhan is much worse due to late starting point and insufficient government support. Empirical investigation and interview towards the operators in the three cities verified this conclusion.

The dominant goal - to satisfy our leisure interests - is concerned with the development of regional economy, leisure ways in different cities, and practical operation performances. The approval degrees and approval percentages of this dominant goal in Shanghai, Chengdu, and Wuhan are 4.44, $4.13,3.42$ and $80 \%, 75 \%$, and $63.2 \%$ respectively. The difference between Shanghai, Chengdu and Wuhan shows that operators in Shanghai and Chengdu, benefiting from their local developed economy, good operation performances and regional leisure ways, care more about their interests and hobbies, while operators in Wuhan care more about making money rather than pursuit of interests and hobbies due to poor operation performances due to inferiority in regional economy and lack of leisure tradition. This was also confirmed in the interview.

The dominant goal -to be able to keep my family together- is concerned with regional traditional custom, practical operation performance and resident status. The approval percentages and approval degrees in Shanghai, Wuhan and Chengdu are 52\%, 63.1\%, 70.9\% and 4.04, 3.37, and 3.54 respectively. Economic development and traditional customs assume a negative correlation. the good operation performance in Shanghai leads to more family attendance to the business, while the poor operation performance in Wuhan results in quite the opposite. The situation in Chengdu is complex, which indicate local operators are not local rural residents, but urban residents, so their family can not get away from their respective jobs and get involved in the operation of rural tourism.

The above shows that operators of rural tourism in Shanghai, Wuhan and Chengdu all have a great favor to rural life, and family cohesion in the three cities is not strong. 
Besides, farm hotels are well operated in Shanghai, which lies in economically developed region in the east, where operators have much more concern about interests and hobbies as well as lifestyle and rural environment. Because traditional conception of operators in Shanghai is not strong, so strengthening family cohesion is rather limited, but luckily, good operation performances leads to the rise of the approval degree. Wuhan is situated in the central part of China with poor farm hotel operation performance; though operators in Wuhan show great fondness to rural environment and lifestyle, the approval degree is rather low; in addition, operators' approval percentage and approval degree in the goal "to satisfy our leisure interests are low, and the approval degree of rural tourism's function in promoting family cohesion is low as well. Chengdu is situated in the west where the economy is most undeveloped. Operators in Chengdu show much concern about lifestyle, rural environment, interests and hobbies because rural tourism got started early and most operators are urban residents; Strong inland traditional conception in Chengdu leads to stronger family cohesion.

\section{B. Money}

The three dominant goals of the recessive goal money are to earn much money, to keep family hotels as family property and to earn retirement income. The approval percentages of the three goals are $76.5 \%, 72.1 \%$ and $69.1 \%$, and the approval degrees are 4.03, 3.96, and 3.79 respectively. As can be seen from the above data, the approval percentage and degree of "to earn much money" by operators in the three cities are higher than the approval percentage and degree of both to keep family hotels as family property and to earn retirement income. That indicates from one side that operators show too much concern about making money.

To earn much money is concerned with the regional economic development which the operators live in, operators' consciousness of making profit and the practical operation performances. The approval percentages of to earn much money by operators in Shanghai, Wuhan and Chengdu are $84 \%, 73.7 \%$ and $70.8 \%$, and the approval degrees are 4.44 , 3.68, and 3.86 respectively. Shanghai is situated in economically developed region where operators have good sense of economy and the practical operation performance is good, so the operators have highest approval percentage and degree of to earn much money, while the economic development of Wuhan is just average and the practical operation performance is poor, so in Wuhan, the operators' approval percentage is just average and the approve degree the lowest, though operators here also have strong sense of making profit. Chengdu is situated in the west whose economy is least developed. Chengdu operators' sense of making profit is not as strong as Shanghai and Wuhan operators'. Therefore, operators in Chengdu have lowest approval percentage of to earn much money. Rural tourism in Chengdu, however, started early and has got mature, and the operation performance is good, so the approval degree is a little higher than that in Wuhan where the operation performance is poor.
To keep family hotels as family property is concerned with the economic development, operators' sense of economy, operators' investment ways and the practical operation performances. Operators' approval percentages in Shanghai, Wuhan and Chengdu are $72 \%, 89.4 \%$ and $62.5 \%$, and the approval degrees are 4.28, 3.58, and 3.92 respectively. Shanghai is economically developed, where operators have strong sense of economy and operators' investment can obtain the collective's support, so the approval degree is the highest among the three cities, though the approval proportion is not high. Economy in Wuhan is just in an ordinary level. In Wuhan, operators mainly invest by themselves with little support from the collective. Therefore, operators in Wuhan have highest approval proportion in rural tourism's property, but the approval degree is rather low because of deviation from the practical operation performance. Though Chengdu is situated in the region where the economy is most undeveloped, operators, thanks to the government's preferential policies, have lowest approval percentage in rural tourism's property. However, the approval degree in Chengdu is higher than that in Wuhan because the operation performance in Chengdu is better .

To earn retirement income is concerned with regional economic development, operators' values and the practical operation performances. Operators' approval percentages in Shanghai, Wuhan and Chengdu are 64\%, 68.4\% and 75\%, and the approval degrees are $4.20,3.53$, and 3.58 respectively. Shanghai is situated in the economically developed region with high income and income pluralism, where operators do not need to care too much about supporting themselves at old age. Therefore, they approve less of the goal to earn retirement income. But Shanghai operators show much approval towards the idea that rural tourism helps to make money for old age. Economy in Wuhan is just developed in an ordinary level. Operators in Wuhan have realized the importance of making money for old age by starting rural tourism, so the approval percentage in Wuhan is higher than in Shanghai, but the approval degree is the lowest because the practical operation performance is poor. Chengdu is situated in the region where the economy is most undeveloped, but the actual operation result is good, operators have the highest approval percentage in the goal to earn retirement income. However, most operators in Chengdu are urban residents whose values are quite different from the operators in Shanghai and Wuhan, their approval degree in the goal to earn retirement income is almost the same as the approval degree in Wuhan.

The above suggests that rural tourism in Shanghai, Wuhan and Chengdu all concerns too much about the economy goal, but too little about the property as well as the problem of supporting themselves at old age. Shanghai is situated in economically developed region where operators have good sense of economy and the practical operation performance is good, so the operators show high approval percentage and degree towards the goals to keep family hotels as family property and to earn much money, but show low approval percentage and highest approval degree towards the 
goal to earn retirement income. Because the economy in Wuhan is not very developed and most operators depend on themselves to invest, so the operators in Wuhan show much concern on rural tourism property. At the same time, poor operation leads to operators' low approval degree in rural tourism property, and causes operators reduce their approval percentage and degree in the goals to earn much money, and "to earn money for old age. Chengdu is situated in the economically undeveloped area, where operators have highest approval proportion in the goal to earn retirement income, besides, most Chengdu operators are urban residents, so they have little sense of rural tourism property.

\section{Social Life}

As to the dominant goal to get acquainted with more interesting people, Shanghai's, Wuhan's and Chengdu's operators' approval percentages are $84 \%, 78.9 \%, 79.1 \%$, and approval degrees 4.48, 3.57, 4.29 respectively. Operators in the three cities all show much approval to the idea that rural tourism can enable them to get acquainted with more interesting people. The puny difference in the approval percentage among three cities shows that a lot of operators in the three cities start rural tourism as a way of social communication and take positive attitude to the idea that they can make more friends by starting their farm hotels. In addition, Wuhan operators' approval degree is obviously lower than that of Shanghai's and Chengdu's operators', which can be explained as poor rural tourism operation in Wuhan, poorer tourist flows, and means fewer chances for operators to get acquainted with tourists.

\section{Self-reliance}

The recessive goal self-reliance includes the three dominant goals, that is, to improve one's own reputation and popularity, to be able to be a boss and to be economically dependent. The approval degree and percentage to be economically dependent (4.29 and $85.3 \%)$ are obviously higher than the approval degree and percentage in the goals to improve one's own reputation and popularity (3.65 and $60.3 \%$ ) and to be able to be a boss (3.21 and 47\%), which indicates that most operators show great interest in making money by starting rural tourism to get rich quickly so as to achieve economic independence, but little interest in improving social popularity and status, which demonstrates the characteristics of rural tourism in its early stage that operators show too much concern to the economy goal but insufficient concern to the social goal of self realization.

As to the goal to be economically dependent, Shanghai's, Wuhan's and Chengdu's operators' approval percentages are $80 \%, 84.3 \%, 91.7 \%$, and approval degrees 4.32, 4.05, 4.46 respectively. Chengdu is situated in the west where the economy is most undeveloped, where most operators are urban residents, and rural tourism operation is good, so operators' approval percentage and degree are both the highest in the goal to start rural tourism to earn money and to make profit so as to achieve economic independence. Shanghai is situated in economically developed area where people have various ways of making money, so the approval percentage in the goal to start rural tourism to achieve economic independence is not as high as that in Wuhan or Chengdu. Due to good rural tourism operation, however, the approval degree in economic independence is also high. Wuhan's economy is just ordinarily developed, so the approval percentage is in the middle. But due to poor rural tourism operation, Wuhan operators' approval degree is the lowest in the goal to start rural tourism to achieve economic independence.

As to the goal to improve one's own reputation and popularity, Shanghai's, Wuhan's and Chengdu's operators' approval percentages are $48 \%, 64.6 \%, 70.9 \%$, and approval degrees $3.88,3.68,3.38$ respectively. There is little difference in the approval percentage and degree among the three cities, but there are some subtle differences: economy development assumes slightly negative correlation with the approval percentage showed by the operators in the three cities in the goal to start rural tourism to improve one's own popularity while positive correlation with the approval degree, which suggests the subtle relation between operators' goal to improve popularity by starting rural tourism and the regional economic development, that is, operators in Chengdu show much concern to the goal "to realize self value" apart from the goal to earn money because rural tourism started early in Chengdu and has got a little mature, while operators in Shanghai show little concern to self realization but much concern to making money because rural tourism started late in Shanghai.

As to the goal "to be able to be a boss", Shanghai's, Wuhan's and Chengdu's operators' approval percentages are $52 \%, 47.3 \%, 41.7 \%$, and approval degrees 3.24, 3.26, 3.13 respectively. There is little difference among the operators in the three cities in the idea that rural tourism can realize their dream to be a boss, which suggests clearly that the operators in the three cities show little concern to self value realization during the early stage of rural tourism.

The above proves that rural tourism operators in Shanghai, Wuhan and Chengdu all show too much concern to the economy goal but insufficient concern to self realization. Chengdu is situated in the area with most undeveloped economy and most operators are urban residents, so operators hope to achieve economic independence by starting rural tourism. Besides, rural tourism started early in Chengdu and has got mature, so Chengdu operators' wishes to realize self value by improving their popularity through rural tourism are the strongest among the three cities. Shanghai is situated in economically developed area where people have various ways of making money, so operators' wishes to start rural tourism to achieve economic independence are not strong. In addition, because rural tourism started late in Shanghai and is not mature, operators' wishes to improve their own popularity by starting rural tourism to realize self value are not strong, either. Wuhan's economy development lies between Shanghai and Chengdu, and its rural tourism operation is not good, so operators' wishes to achieve economic independence and to improve their own popularity are just not so strong. 
To sum up, rural tourism operators in the three cities all show strong favour to rural life, too much concern to the economy goal but insufficient concern to the goals to earn money for old age, to take rural tourism as family property and to realize self value, and family cohesion of rural tourism is not strong and operators have strong motivation for social communication, which reflects the common characteristics of rural tourism in its early stage. The differences in the three cities' operators' opinions about the start-up goals of rural tourism are as follows: because of developed economy, operators' strong sense of economy, weak conception of tradition and good operation of rural tourism, Shanghai operators show much concern to lifestyle, rural environment, interests and hobbies, rural tourism property, and profit, low approval percentage but highest approval degree towards the goal "to earn money for old age", and their wishes to achieve economic independence and to improve their own popularity are not strong, besides, the approval percentage is low in the idea that rural tourism can promote family cohesion. Wuhan's economy is just ordinarily developed, so operators have strong sense of economy and traditional conception, but the operation of rural tourism is poor in Wuhan, therefore, even though operators show much approval to lifestyle and rural life, they show little approval to the goals to satisfy their own interests and hobbies, to earn money and to earn money for old age. Besides, most operators in Wuhan depend on themselves to invest in rural tourism, so the approval percentage in rural tourism property is high. Chengdu is situated in the west where the economy is most undeveloped, so operators have little sense of economy but strong conception of tradition. However, rural tourism started early in Chengdu, and most operators are non-local urban residents, so operators in Chengdu show much concern to the goals to earn money for old age, to be economically independent and to improve their own popularity as well as lifestyle, rural environment and interests and hobbies. The approve percentage shown by the operators in Chengdu in the idea that rural tourism can promote family cohesion is high, but the actual approval degree is not high enough. Operators' sense of property and sense of earning money and making profit by starting rural tourism are low as well.

\section{Conclusion}

Through the analysis of the investigation conclusion about the start-up goals of rural tourism operators in the three cities, it can be concluded that operators in the three cities show an overall confirmation to these start-up goals. Operators' hopes to earn money and to make profit so as to achieve economic independence are based on their strong affection to rural life and strong motivation for social communication. The start-up goals in the three cities reflect the characteristics of rural tourism in its early stage, that is, strong attachment to rural life, too much concern about economic benefit but insufficient concern about self value realization. Shanghai operators show much concern to interests and hobbies, rural tourism property, money and profit, and social life, but insufficient concern to the goals to earn money for old age, to be economically independent, to improve their own popularity and to promote family cohesion. Wuhan operators show little approval to the goals to satisfy one's own interests and hobbies, to earn much money and to earn money for old age, but they show much concern to rural tourism property. Chengdu operators show much concern to the goals to satisfy one's own interests and hobbies, to earn money for old age, to be economically independent, to improve one's own popularity and to promote family cohesion through rural tourism, but their sense of earning much money as well as rural tourism property is low.

This article objected to the subject of rural tourism operation - operators. There is little study on this subject in China at present. Through the analysis of the conclusion of the empirical investigation into the three cities' rural tourism operators' start-up goals, it was found that their start-up goals demonstrate some common characteristics of rural tourism in its early stage, but there are also some differences. Each city also has its own characteristics in choosing the start-up goals. Operators in the three cities show too much concern to the short-term economy goal but little concern to the long-term economy goal and the goal to realize self value, so it is urgent for governmental departments to provide related training and guidance. Therefore, the study of this article is of practical significance to the healthy development of rural tourism in the three cities and even in China. Meanwhile, the study on rural tourism operators' start-up goals in this article also enriches the content of rural tourism study in China, and fills the gap in China in empirical study on operators' goals for starting rural tourism, so it is also of theoretical significance.

\section{Acknowledgment}

This research was financially supported by "Education Training of New Professional Farmers Based on Action Mechanism of Rural Tourism on Farmers' Competences in Tourist Destination Community" (Funded by the Education Department of Henan Province Grant No. : ZJA14102) ;

"Education Training of New Agricultural Management Subject Leaders in Henan Province" (Funded by the Education Department of Henan Province Grant No. : ZJA14001) ; "Education Training of New Professional Farmers in Henan Province" (Funded by the Education Department of Henan Province Grant No. : ZJA14101).

\section{References}

[1] Wenchang Sun, Modern Tourism Development, Qingdao : Qingdao Press, 2001,pp.226.

[2] Guihua Yang, Xiuhong Wang, Rural Tourism Management Manual. Beijing: China Tourism Press, 2006, pp.1-32.

[3] Oppermann. M, "Rural Tourism in Southern Germany", Annals of Tourism Research,vol.23,no.1,pp,86-102,1996

[4] Jun Wen, Meicai Wei, "Discussion about Rural Tourism Development Mode", Ecological Economy,Vol,6,pp.125-127, 2002

[5] Donald Getz, Jack Carlsen, "Characteristics and goals of family and owner-operated businesses in the rural tourism and hospitality sectors ”,Tourism Management, vol.21,pp.547-560,2000 